\title{
Socio-demographic profile of reproductive tract infections and sexually transmitted diseases in reproductive aged women
}

\author{
Uma Gupta $^{1 *}$, Parul Sinha ${ }^{1}$, Lubna Inam ${ }^{1}$, Shuchi Gupta ${ }^{2}$
}

${ }^{1}$ Department of Obstetrics \& Gynaecology, Eras Lucknow Medical College, Lucknow, Uttar Pradesh, India
${ }^{2}$ Department of Obstetrics \& Gynaecology, Hind Institute of Medical Sciences, Lucknow, Uttar Pradesh, India

Received: 27 February 2015

Accepted: 19 April 2015

\section{*Correspondence:}

Dr. Uma Gupta,

E-mail: umankgupta@gmail.com

Copyright: (C) the author(s), publisher and licensee Medip Academy. This is an open-access article distributed under the terms of the Creative Commons Attribution Non-Commercial License, which permits unrestricted non-commercial use, distribution, and reproduction in any medium, provided the original work is properly cited.

\begin{abstract}
Background: RTI including Sexually Transmitted Diseases (STD) are increasingly recognized as a major cause of morbidity in India. RTI have become widespread today because of the changing social fabric and unconventional sexual behaviors. The present study was done to assess the prevalence of RTI and STD in women aged 20-45 years and to correlate the socio-demographic factors with RTI \& STD.

Methods: Two hundred \& fifty women in the age group of 20-45 years attending the outpatient department of Obstetrics and Gynecology of VPC \& IMS, Lucknow were included in the study. Out of them 215 were symptomatic and 35 were asymptomatic. All of them were offered clinical and microbiological examinations. A pretested, semistructured interview schedule was used.

Results: In this study the prevalence of RTI/STD was higher among women aged 31-35years, rural population, illiterate \& less educated (90.4-97\%) females, in farm workers \& in students. The females having toilet access in field $\&$ outside toilet and with poor personal and menstrual hygiene, had more prevalence of RTI/STD.

Conclusions: Hence we as obstetricians should try to make public aware about the importance of RTI/STD prevention, early diagnosis and prompt and complete treatment to avoid long term squealae.
\end{abstract}

Keywords: RTI, STD, Sexual \& reproductive health, Socio-demographic factors

\section{INTRODUCTION}

The concept of sexual and reproductive health was first fully articulated at International conference on population and development at Cairo in 1994 \& the Government of India has launched reproductive and child health programme in 1997 with special emphasis on management of Reproductive Tract Infections (RTI). ${ }^{1}$ RTI including Sexually Transmitted Diseases (STD) are increasingly recognized as a major cause of morbidity in India. The importance of control of RTI has increased with the introduction of HIV/AIDS epidemics in the country. ${ }^{2}$ RTI have become widespread today because of the changing social fabric and unconventional sexual behaviors. The incidence of RTI is now reaching enormous proportion globally. According to World Health Organization (WHO), the estimated figures of four major STDs in women in the reproductive age groups are 12.2 millions for syphilis, 167.2 millions for Trichomonas, and 62.2 million for Gonorrhea \& 89.1 millions for Chlamydia infections. ${ }^{3}$ RTI pose grave threats to women's lives worldwide. These infections may be sexually transmitted or caused by unsafe medical procedures or due to overgrowth of organisms that normally inhabit the genital tract. ${ }^{4}$ RTI are associated with adverse health outcomes such as intrauterine growth restriction (IUGR), premature labor and increase vulnerability of HIV/AIDS. ${ }^{5}$ The most serious long term sequelae arising in women are: pelvic inflammatory disease (PID), cervical cancer, infertility, spontaneous 
abortion and ectopic pregnancy, the latter of which may lead to death. ${ }^{6}$

\section{Aims \& objectives}

The present study was done with following aims and objectives:

1. To assess the prevalence of RTI and STD in women aged 20-45 years.

2. To correlate the socio-demographic factors with RTI \& STD.

\section{METHODS}

The present study was conducted in the department of Obstetrics and Gynecology in association with the department of Pathology and Microbiology of Vivekananda Polyclinic and Institute of Medical Sciences (VPC \& IMS), Lucknow. Two hundred \& fifty women in the age group of 20-45 years attending the Outpatient department of Obstetrics and Gynecology of VPC \& IMS, Lucknow were included in the study.

\section{Inclusion criteria}

- Sexually Active.

- 20-45 years of age.

- Pregnant/Non Pregnant both.

- Diabetic/non diabetic both.

- On oral contraceptives.

- Those who gave informed consent.

\section{Exclusion criteria}

- Women on Immunosuppressive therapy.

- Women on Anti-cancer therapy.

- Women who were known case of chronic disease that might compromise immune System.

A total of 250 women were interviewed, out of them 215 were symptomatic and 35 were asymptomatic. All of them were offered clinical and microbiological examinations.

A pretested, semi-structured interview schedule was used. Women were asked about their age, age at marriage, education, parity, type of contraceptive methods used, history of gynecological surgical interventions \& whether they have any problem related to reproductive tract, history of blood transfusion, obstetric history, followed by direct questions on the presence of unusual vaginal discharge, vulval itching, pain during menstruation, premenstrual congestion, irregular menstruation, lower abdominal pain, low backache \& pain during sexual intercourse.

The laboratory work was conducted in the department of Pathology and Microbiology of VPC \& IMS, Lucknow.

\section{Collection and transport of specimens}

After taking the informed consent, per speculum examination was done under aseptic conditions and the condition of vagina, nature of discharge (amount, color, consistency etc.) \& the condition of the cervix was noted. After that vaginal swab was taken from the posterior vaginal fornix with the help of two separate sterile swab sticks \& put into a sterile test tube and sent for Gram staining and culture \& sensitivity.

\section{RESULTS}

Out of 250 subjects enrolled, 208 (83.2\%) had Reproductive Tract Infection (RTI) whereas $1(0.4 \%)$ had Sexually Transmitted Disease (STD), 12 (4.8\%) cases had both RTI and STD. However, in 29 (11.6\%) cases, neither STD nor RTI was proved. Thus the prevalence of STD amongst patients was around 5.2\%. All the cases of STD, except for 1 case had some or other problem that could be referred to as RTI (Table 1).

Table 1: Type of disease $(n=250)$.

\begin{tabular}{|ll|l|}
\hline Type of disease & No. & $\%$ \\
\hline RTI & 208 & 83.2 \\
\hline STD & 1 & 0.4 \\
\hline RTI+STD & 12 & 4.8 \\
\hline No RTI/STD & 29 & 11.6 \\
\hline
\end{tabular}

Table 2: Age wise distribution $(n=250)$.

\begin{tabular}{|c|c|c|c|c|c|c|}
\hline \multirow[t]{2}{*}{$\begin{array}{l}\text { Age } \\
\text { group } \\
\text { (years) }\end{array}$} & \multicolumn{2}{|c|}{$\begin{array}{l}\text { RTI/STD } \\
\text { Present } \\
(\mathbf{n}=\mathbf{2 2 1})\end{array}$} & \multicolumn{2}{|c|}{$\begin{array}{l}\text { RTI/STD } \\
\text { Absent } \\
(n=29)\end{array}$} & \multicolumn{2}{|c|}{ Total } \\
\hline & No. & $\%$ & No. & $\%$ & No. & $\%$ \\
\hline $20-25$ & 53 & 85.5 & 9 & 14.5 & 62 & 24.8 \\
\hline $26-30$ & 54 & 87.1 & 8 & 12.9 & 62 & 24.8 \\
\hline $31-35$ & 53 & 93.0 & 4 & 7.0 & 57 & 22.8 \\
\hline $36-40$ & 39 & 88.6 & 5 & 11.4 & 44 & 17.6 \\
\hline $41-45$ & 22 & 88.0 & 3 & 12.0 & 25 & 10.0 \\
\hline
\end{tabular}

$\chi^{2}=1.790(\mathrm{df}=4) ; \mathrm{P}=0.774$

There were $62(24.8 \%)$ patients each in age group 20-25 and 26-30 years respectively followed by age group 3135 years $(n=57 ; 22.8 \%)$. In age group $36-40$ years, there were $44(17.6 \%)$ patients while in age group 41-45 years, there were only $25(10 \%)$ patients. It was seen that the prevalence of RTI/STD was highest (93\%) among 
women aged 31-35years (Table 2). Mean age of the subjects was $31.31 \pm 6.80$ years with a minimum of 20 years and a maximum of 45 years.

Table 3: Demographic Information $(n=250)$.

\begin{tabular}{|c|c|c|c|c|c|c|}
\hline \multirow[t]{2}{*}{ Variable } & \multicolumn{2}{|c|}{$\begin{array}{l}\text { RTI/STD } \\
\text { Present } \\
(\mathbf{n}=221)\end{array}$} & \multicolumn{2}{|c|}{$\begin{array}{l}\text { RTI/STD } \\
\text { Absent } \\
(n=29)\end{array}$} & \multicolumn{2}{|c|}{$\begin{array}{l}\text { Total } \\
(n=250)\end{array}$} \\
\hline & No. & $\%$ & No. & $\%$ & No. & $\%$ \\
\hline \multicolumn{7}{|l|}{ Location* } \\
\hline Urban & 137 & 84.6 & 25 & 15.4 & 162 & 64.8 \\
\hline Rural & 84 & 95.5 & 4 & 4.5 & 88 & 35.2 \\
\hline \multicolumn{7}{|l|}{ Education } \\
\hline Illiterate & 47 & 90.4 & 5 & 9.6 & 52 & 20.8 \\
\hline Primary & 39 & 92.9 & 3 & 7.1 & 42 & 16.8 \\
\hline High School & 32 & 97.0 & 1 & 3.0 & 33 & 13.2 \\
\hline Intermediate & 29 & 90.6 & 3 & 9.4 & 32 & 12.8 \\
\hline Graduate & 50 & 80.6 & 12 & 19.4 & 62 & 24.8 \\
\hline PG or above & 24 & 82.8 & 5 & 17.2 & 29 & 11.6 \\
\hline \multicolumn{7}{|l|}{ Marital status } \\
\hline Married & 211 & 87.9 & 29 & 12.1 & 240 & 96.0 \\
\hline Remarriage & 6 & 100.0 & 0 & 0.0 & 6 & 2.4 \\
\hline Separated & 2 & 100.0 & 0 & 0.0 & 2 & 0.8 \\
\hline Unmarried & 1 & 100.0 & 0 & 0.0 & 1 & 0.4 \\
\hline Widow & 1 & 100.0 & 0 & 0.0 & 1 & 0.4 \\
\hline \multicolumn{7}{|l|}{ Occupation } \\
\hline Self employed & 4 & 80.0 & 1 & 20.0 & 5 & 2 \\
\hline Professional & 0 & 0.0 & 1 & 100.0 & 1 & 0.4 \\
\hline $\begin{array}{l}\text { Farm work / } \\
\text { Menial work }\end{array}$ & 12 & 100.0 & 0 & 0.0 & 12 & 4.8 \\
\hline Homemaker & 183 & 88.0 & 25 & 12.0 & 208 & 83.2 \\
\hline Service/Teacher & 19 & 90.5 & 2 & 9.5 & 21 & 8.4 \\
\hline Student & 3 & 100.0 & 0 & 0.0 & 3 & 1.2 \\
\hline \multicolumn{7}{|c|}{ Socioeconomic status } \\
\hline Lower & 56 & 96.6 & 2 & 3.4 & 58 & 23.2 \\
\hline Upper lower & 54 & 90.0 & 6 & 10.0 & 60 & 24 \\
\hline Lower middle & 61 & 84.7 & 11 & 15.3 & 72 & 28.8 \\
\hline Upper middle & 31 & 88.6 & 4 & 11.4 & 35 & 14 \\
\hline Upper & 19 & 76.0 & 6 & 24.0 & 25 & 10 \\
\hline \multicolumn{7}{|l|}{ Toilet access } \\
\hline Field & 52 & 96.3 & 2 & 3.7 & 54 & 21.6 \\
\hline In house & 120 & 85.7 & 20 & 14.3 & 140 & 56 \\
\hline Outside & 49 & 87.5 & 7 & 12.5 & 56 & 22.4 \\
\hline
\end{tabular}

$* \mathrm{P}<0.05$ - Statistically significant

A total of $162(64.8 \%)$ patients were urban and remaining $88(35.2 \%)$ were rural. The prevalence of RTI/STD was significantly higher $(95.5 \%)$ amongst ruralites as compared to urbanites $(84.6 \%)(\mathrm{P}=0.010)$.

The rate of literacy among enrolled subjects was $79.2 \%$, with $91(36.4 \%)$ subjects educated up to graduate or above. Only $52(20.8 \%)$ respondents were illiterate. The prevalence of RTI/STD was low among highly educated women.
There were $240(96 \%)$ subjects who were married once, 6 $(2.4 \%)$ had remarriage, $2(0.8 \%)$ were separated, $1(0.4 \%)$ patient was widow while another $(0.4 \%)$ was unmarried. No significant association between RTI/STD and marital status could be seen $(\mathrm{P}=0.850)$.

Eighty-three percent reported that their sole occupation was performing household chores and taking care of young children. In addition to running a household, $8.4 \%$ were doing Service/Teachers, $4.8 \%$ were related to farm work, $2 \%$ were self-employed, $1.2 \%$ were students \& $0.4 \%$ were professional. The prevalence of RTI/STD was highest among farm workers and students. No significant association between RTI/STD and occupation could be seen $(\mathrm{P}=0.074)$.

The subjects hailed from almost all the socioeconomic strata, however, lower middle class subjects (28.8\%) were maximum in number while those coming from upper socioeconomic strata comprised the smallest class (10\%). RTI/STD was more common in lower socioeconomic strata $(96.6 \%)$ \& least common in upper socioeconomic strata.

Toilet access was in fields for $54(21.6 \%)$ subjects, in house toilet was available to majority $140(56 \%)$ while a $56(22.4 \%)$ were using toilet outside their homes. It was seen people having toilet access in field \& outside toilet were more suffering from RTI/STD $(96.3 \%) \&(87.5 \%)$ respectively in comparison to in house toilet access (85.7\%). No significant association between type of toilet facility being used and RTI/STD could be seen $(\mathrm{P}=$ 0.116) (Table 3).

Table 4: Distribution of women in relation to education \& location.

\begin{tabular}{|llllll|} 
Education & \multicolumn{2}{l}{$\begin{array}{l}\text { Rocation } \\
\text { Rural }\end{array}$} & \multicolumn{2}{l}{$\begin{array}{l}\text { Urban } \\
\text { (n=84) }\end{array}$} & \multicolumn{2}{l}{ Total } \\
& No. & \% & No. & \% & \\
\cline { 2 - 5 }$(\mathbf{n}=221)$ & \\
\hline Illiterate & 35 & 74.5 & 12 & 25.5 & $47(21.2 \%)$ \\
\hline Primary & 20 & 51.0 & 19 & 48.7 & $39(17.6 \%)$ \\
\hline High school & 14 & 43.7 & 18 & 56.2 & $32(14.4 \%)$ \\
\hline Intermediate & 9.0 & 31.0 & 20 & 69.0 & $29(13.1 \%)$ \\
\hline Graduate & 4.0 & 8.0 & 46 & 92.0 & $50(22.6 \%)$ \\
\hline P.G. & 2.0 & 8.3 & 22 & 91.6 & $24(10.8 \%)$ \\
\hline
\end{tabular}

$\chi^{2}=75.50 ; \mathrm{P}<0.001$

Out of 221 women with RTI/STD, $21.2 \%$ were found to be illiterate. The level of illiteracy was higher $(74.5 \%)$ among rural than the urban $(25.5 \%)$. It was seen that in rural group, the number of subjects with lower education was significantly higher as compared to urban group, implying that urban subjects were significantly more educated as compared to rural subjects $(\mathrm{P}<0.001)$ statistically significant (Table 4). 
Table 5: Distribution of women according to sexual behavior and contraceptive practices $(n=250)$.

\begin{tabular}{|c|c|c|c|c|c|c|}
\hline \multirow[t]{2}{*}{ Variable } & \multicolumn{2}{|c|}{$\begin{array}{l}\text { With } \\
\text { RTI/STD } \\
(\mathbf{n}=\mathbf{2 2 1})\end{array}$} & \multicolumn{2}{|c|}{$\begin{array}{l}\text { Without } \\
\text { RTI/STD } \\
(\mathrm{n}=\mathbf{2 9})\end{array}$} & \multicolumn{2}{|c|}{$\begin{array}{l}\text { Total } \\
(n=250)\end{array}$} \\
\hline & No. & $\%$ & No. & $\%$ & No. & $\%$ \\
\hline \multicolumn{7}{|c|}{ No. of sexual partners } \\
\hline None & 1.0 & 100 & 0 & 0 & 1.0 & 0.4 \\
\hline Uniandrous & 215 & 88.1 & 29 & 11.9 & 244 & 97.6 \\
\hline Polyandry & 5.0 & 100 & 0 & 0 & 5.0 & 2.0 \\
\hline \multicolumn{7}{|c|}{ Poly vs. Uniandrous: $\chi^{2}=0.673 ; \mathrm{P}=0.412$} \\
\hline \multicolumn{7}{|c|}{ Contraceptive methods used } \\
\hline None & 105 & 87.5 & 15 & 12.5 & 120 & 48 \\
\hline Barrier & 35 & 79.5 & 9 & 20.5 & 44 & 17.6 \\
\hline I.U.C.D. & 15 & 88.2 & 2 & 11.8 & 17 & 6.8 \\
\hline O.C.P. & 12 & 100.0 & 0 & 0.0 & 12 & 4.8 \\
\hline Injectable & 1 & 100.0 & 0 & 0.0 & 1 & 0.4 \\
\hline Sterilization & 53 & 94.6 & 3 & 5.4 & 56 & 22.4 \\
\hline
\end{tabular}

Ninety seven percent of the women were uniandrous. No significant association between number of sexual partners and RTI/STD was seen $(\mathrm{P}=0.412)$.

Sterilization was most common contraceptive method used $(22.4 \%)$, barrier method was used by $17.6 \%$ women $\&$ rest methods were less accepted. The incidence of RTI/STD was lesser in women using barrier method (79.5\%) in comparison to other methods (Table 5).

Table 6: Personal and menstrual hygiene $(n=250)$.

\begin{tabular}{|c|c|c|c|c|c|c|}
\hline \multirow[t]{2}{*}{ Variable } & \multicolumn{2}{|c|}{$\begin{array}{l}\text { RTI/STD } \\
\text { Present } \\
(\mathbf{n}=221)\end{array}$} & \multicolumn{2}{|c|}{$\begin{array}{l}\text { RTI/STD } \\
\text { Absent } \\
(\mathrm{n}=29)\end{array}$} & \multicolumn{2}{|c|}{$\begin{array}{l}\text { Total } \\
(\mathrm{n}=\mathbf{2 5 0})\end{array}$} \\
\hline & No. & $\%$ & No. & $\%$ & No. & $\%$ \\
\hline \multicolumn{7}{|c|}{ Personal hygiene } \\
\hline Good & 20 & 76.9 & 6 & 23.1 & 26 & 10.4 \\
\hline Fair & 129 & 87.8 & 18 & 12.2 & 147 & 58.8 \\
\hline Poor & 72 & 93.5 & 5.0 & 6.4 & 77 & 30.8 \\
\hline \multicolumn{7}{|c|}{$\chi^{2}=5.357(\mathrm{df}=2) ; \mathrm{P}=0.069$} \\
\hline \multicolumn{7}{|c|}{ Menstrual hygiene } \\
\hline Good & 25 & 73.5 & 9 & 26.5 & 34 & 13.6 \\
\hline Fair & 108 & 90.8 & 11 & 9.2 & 119 & 47.6 \\
\hline Poor & 88 & 90.7 & 9 & 9.3 & 97 & 38.8 \\
\hline
\end{tabular}

Personal hygiene was seen to be poor in 77 (30.8\%) of patients whereas menstrual hygiene was poor in 97 (38.8\%) patients. Though the incidence of RTI/STD was higher among those with poor hygiene yet it was statistically not significant as regards personal hygiene while it was significant for menstrual hygiene $(\mathrm{P}=0.014)$ (Table 6).

\section{DISCUSSION}

Present study revealed that the prevalence of RTI/STD was highest (93\%) among women aged 31-35 years (Table 2). This is comparable with the study of Rathore et al. ${ }^{7}$ which also showed the highest prevalence of RTI in women aged 30-34 years. Sharma \& Gupta $^{8}$ found maximum prevalence of RTI/STD between 25-34 years of age. Similarly Gupta et al. ${ }^{9}$ showed that commonest affected age group was 26-35years which is a period of maximal sexual and reproductive activity. This may be explained by the facts that with increasing age women experienced longer married life, pregnancies, gynecological surgeries, deliveries, use of invasive contraceptives; these make women more vulnerable to RTIs. This explanation is further supported by the observation made in the present study that RTI/STD were more common in multi and grand multi than nulligravida.

Pant et al. ${ }^{10}$ showed the prevalence of RTI was significantly higher in women who were married at an age below 18 years as compared to women who got married above 18 years. This indicates that early sex and pregnancy are too early and risky for girls in every way, lengthening the span of years over which they have children and increasing the risk of infections. Young women are particularly susceptible to RTI/STD because they have fewer antibodies to fight pathogens and greater cervical ectopy.

The present study revealed that the prevalence of RTI/STD was significantly higher $(95.5 \%)(\mathrm{P}=0.010)$ amongst rural population as compared to urban population (Table 3) which is comparable with study by Panda et al. ${ }^{11} \&$ Deokinandan et al. ${ }^{12}$ which also showed that the prevalence of RTI/STD is higher in rural population in comparison to urban population. The reason behind this is that the health services are not equally distributed so they are less accessible for rural population and also because of lack of awareness in rural population.

The present study showed that prevalence of RTI/STD was low among highly educated females (80.6\%-82.8\%) in comparison to less educated and illiterate women (90.4\%-97\%) (Table 3). This finding was similar to the findings of Panda et al., ${ }^{11}$ Deokinandan et al., ${ }^{12}$ Data from NFHS-II and Pawanarkar, ${ }^{13}$ Ranjan et al., ${ }^{14}$ Pant et al., ${ }^{10}$ Rathore et al. ${ }^{7} \&$ Datey et al. ${ }^{15}$

In the present study it was seen that in rural group, the prevalence of females with RTI/STD and low education was significantly higher $(\mathrm{P}<0.001)$ as compared to urban group, which were more educated. The level of illiteracy was higher $(74.5 \% ; 35)$ among rural than urban $(25.5 \%$; 12) women (Table 4). This is comparable with study of Pant et al. ${ }^{10}$ which also showed that the level of illiteracy in women of RTI/STD was higher (73\%) among rural than the urban $58 \%$. Substandard hygiene and traditional taboos against openness about these diseases are the usual factors responsible for this high prevalence. 
In the present study majority of the women were homemaker $(83.2 \%)$, in which RTI/STD present in $88 \%$ of the women. The prevalence of RTI/STD was found to be $100 \%$ in farm workers \& students, $90.5 \%$ in service class, $80 \%$ in self-employed women, absent in professional (doctor) (Table 3). This is explained by the fact that working women were preoccupied and did not care for themselves $\&$ neglect their own health. They use common toilet in their working area. Almost all the farm workers are daily wages laborers. They have scarcity of time $\&$ money for themselves to seek medical advice and also they have no knowledge about hygiene \& RTI/STD. This is similar to the findings of Prasad et al. ${ }^{16}$ Which showed occupation was significant factor in STI risk. Women who were agricultural laborers had elevated odds of STIs compared with those who worked solely in the home. The focus group \& key informant data suggested that sexual activity is common among workers in agricultural fields.

The present study showed that the prevalence of RTI/STD was highest $(96.6 \%) \&(90 \%)$ among women belonging to lower \& upper lower socioeconomic strata respectively (Table 3 ) which is comparable with the study by Sinha \& Mishra ${ }^{4}$ and Saxena \& Yadav $^{17}$ which also showed higher prevalence in lower \& upper lower class. Ranjan et al. ${ }^{14}$ in their study showed maximum prevalence $(45 \%)$ in upper middle group, followed by lower middle $(28.3 \%) \&(25.7 \%)$ in lower class. Forty four percent of the women in the present study were using outside toilet $(22.4 \%) \&$ field $(21.6 \%)$ for their bladder \& bowel habits, of which $96.3 \%$ using field \& $87.5 \%$ using outside/public toilet had RTI/STD in comparison to $85.7 \%$ in women using in house toilet. This is comparable with Patel et al. ${ }^{18}$ which also showed higher prevalence of RTI/STD in women who had lack of toilet access in home.

The present study showed $97.6 \%$ were uniandrous \& only $2 \%$ were polyandry. The polyandry women were less because women concealed their sexual behaviour. The prevalence of RTI/STD was $88.1 \%$ among uniandrous \& $100 \%$ among polyandry (Table 5). One or the other method of contraception was used by $52 \%$ \& $48 \%$ were not using any contraception. Tubectomy (sterilization) was the most common (23.9\%) contraceptive method used (Table 5) which is comparable with the study of Rathore et al. $(67 \%)^{7} \&$ Acharya et al. $(37.7 \%) .{ }^{19}$ The prevalence of RTI/STD was low in women using barrier method $(79.5 \%)$ in comparison to other contraceptive methods (88.2-100\%) \& non users $(87.5 \%)$, which is comparable with the findings of Sinha \& Mishra ${ }^{4}$ and Pant et al. ${ }^{10}$ showing RTI cases were lowest in the condom users, but higher among those who used other methods of contraception or no method at all. Barrier contraceptives are known to provide protection against RTI/STD. We feel that abandonment of the barrier contraceptives in favour of sterilization, for which government is giving incentives, has deprived women of potentially effective methods of preventing RTI/STD.
Sterilization was associated with higher risk of RTI/STD, perhaps owing to the fact that women who have been sterilized are less likely to engage in protected sexual intercourse because of the absence of risk of an unwanted pregnancy.

The present study found that the prevalence RTI/STD was higher $93.5 \%$ \& $90.7 \%$ with poor personal and menstrual hygiene, respectively. The prevalence of RTI/STD was significantly associated with menstrual hygiene $(\mathrm{P}=0.014)$ (Table 6$)$. This is similar with the findings of Rathore et al., ${ }^{7}$ Sinha \& Mishra ${ }^{4}$ and Pant et al. ${ }^{10}$ which showed the higher prevalence of RTI among women with poor hygiene.

Thus we have seen that there are different types of reproductive tract infections and sexually transmitted diseases associated with unhygienic delivery and other unsanitary practices. Women are reservoir of all these infections while men are vectors. So females are more susceptible to these infections and are more prone to develop complications because infection in women is difficult to diagnose and is therefore more likely to go untreated.

\section{CONCLUSION}

RTI/STD prevalence in a society has a great impact on sexual and reproductive health of women and also on her unborn child. In this study the prevalence of RTI/STD was higher among women aged 31-35 years, rural population, illiterate \& less educated (90.4-97\%) females, in farm workers \& in students. The females having toilet access in field \& outside toilet and with poor personal and menstrual hygiene, had more prevalence of RTI/STD Hence we obstetrician should try to make public aware about the importance of RTI/STD prevention, early diagnosis and prompt and complete treatment to avoid long term squealae.

\section{Funding: No funding sources Conflict of interest: None declared \\ Ethical approval: The study was approved by the institutional ethics committee}

\section{REFERENCES}

1. National Institute of Health and Family Welfare. Reproductive \& child health module for medical officers. In NIHFW, eds. A Report. New Delhi: National Institute of Health \& Family Welfare; 2000.

2. NACO-Online. Family welfare programme in India, 2004. Available at: http://www.nacoonline.org/prog_sche_campaign.htm Accessed July 2004.

3. Gerbase AC, Rowley JT, Mertens TE. Global epidemiology of sexually transmitted diseases. Lancet. 1998;351(Suppl 3):2-4. 
4. Sinha HH, Mishra MG. Socio demographic Profile \& clinical evaluation of RTIs in rural women of Patna, J Obstet Gynecol India. 2001 Nov/Dec;51(6):124-6.

5. Wasserheit J, Holmes KJ. Reproductive tract infections: challenges for international health, policy, programme \& research. In: Germain A, Holmes K, Pilot P, Wasserheit J, eds. Reproductive Tract Infections: Global Impact \& Priorities for Women's Reproductive Health. New York: Plenum Press; 1992: 7-33.

6. WHO. Global prevalence \& incidence of selected curable sexually transmitted infections. In: WHO, eds. Overview \& Estimates, Geneva: WHO, 2001; \& Cates W Rolfs RJ, Aral SO. Sexually transmitted diseases, pelvic inflammatory disease, \& infertility: an epidemiologic update. Epidemiol Rev. 1990;12:199-221.

7. Rathore M, Vyas L, Bhardwaj AK. Prevalence of Reproductive Tract Infections amongst ever married women and sociocultural factors associated with it. J Indian Med Assoc. 2007;105:71-4, 78.

8. Sharma S, Gupta BP. The prevalence of reproductive tract infections and sexually transmitted diseases among women in the reproductive age group in a rural area. Indian J Community Med. 2009;34(1):624.

9. Gupta V, Gupta P, Chatterjee B, Bansal R. Clinicomicrobiological profile of women with vaginal discharge. Int J Gynecol Obstet India. 2006 JulAug;9(4):46-8.

10. Pant B, Singh JV, Bhatnagar M, Garg SK, Chopra H, Bajpai SK. Social correlates in reproductive tract infections among married women in rural area of Meerut. Indian J Community Med. 2008 Jan;33(1):52-3.

11. Panda SC, Sarangi L, Bebartta D, Parida S, Panigarhi OP. Prevalence of RTI/STI among women of reproductive age in district Sundergarh (Orissa) Indmedica. Indian J Pract Doct. 2007;4(1):516.
12. Deoki Nandan, Mishra SK, Sharma A, Jain M. Estimation of prevalence of RTI/STD among women of reproductive age group in district Agra. Indian J Community Med. 2002 Jul-Sep;27(3):110-3.

13. Pawanarkar J, Chopra K. Prevalence of lower reproductive tract infection in infertile women. Health Popul Perspect Issues. 2004;27(2)67-75.

14. Ranjan R, Sharma AK, Mehta G. Evaluation of WHO diagnostic algorithm for reproductive tract infections among married women. Indian J Community Med. 2003 Apr-Jun;28(2):81-4.

15. Datey S, Bedi N, Gaur LN, Saxena NC, Saxena BN. Sexually transmitted infections (STIs) among antenatal women at five tertiary level hospitals in India. J Obstet Gynecol India. 2003 Jan/Feb;53(1):53-8.

16. Prasad JH, Abraham S, Kurz MK, George V, Lalitha MK, John R, et al. Reproductive tract infections among young married women in Tamil Nadu, India. Int Fam Plan Perspect. 2005;31(2):73-82.

17. Saxena U, Yadav S. STD prevalence in sexually active women attending the STD clinic of a tertiary level general hospital. J Obstet Gynaecol India, 2001;51:134-7.

18. Patel V, Weiss HA, Mabey D, West B, D'Souza S, Patil V, et al. The burden and determinants of reproductive tract infections in India: a population based study of women in Goa, India. Sex Transmit Infect. 2006;82:243-9.

19. Acharya A, Yadav K, Baridalyne N. Reproductive tract infections/ sexually transmitted infections in rural Haryana: experience from the family health awareness Campaign. Indian J Community Med. 2006 Oct-Dec;31(4):274-6.

DOI: $10.18203 / 2320-1770 . i j r \operatorname{cog} 20150058$

Cite this article as: Gupta U, Sinha P, Inam L, Gupta S. Socio-demographic profile of reproductive tract infections and sexually transmitted diseases in reproductive aged women. Int $\mathrm{J}$ Reprod Contracept Obstet Gynecol 2015;4:595-600. 